\title{
Right-to-left shunt through patent foramen ovale during off-pump coronary artery bypass
}

\author{
Mariko Morita, MD, ${ }^{a}$ Hiroshi Inoue, $\mathrm{MD},{ }^{\mathrm{a}}$ and Atsushi Amano, $\mathrm{MD}, \mathrm{PhD},{ }^{\mathrm{b}}$ Sendai and Tokyo, Japan
}

\footnotetext{
From the ${ }^{a}$ Department of Anesthesia, Sendai Kousei Hospital, Sendai; and ${ }^{\mathrm{b}}$ Department of Cardiovascular Surgery, Juntendo University, Tokyo, Japan.

Disclosures: Authors have nothing to disclose with regard to commercial support.

Received for publication Aug 25, 2015; revisions received Nov 20, 2015; accepted for publication Dec 1, 2015; available ahead of print Jan 22, 2016.

Address for reprints: Mariko Morita, MD, Department of Anesthesia, Sendai Kousei Hospital, 4-15 Hirose-machi, Aoba-ku, Sendai-city, Miyagi, Japan (E-mail: marimorita-tky@umin.ac.jp).

J Thorac Cardiovasc Surg 2016;152:e21-2

$0022-5223 / \$ 36.00$

Copyright (c) 2016 by The American Association for Thoracic Surgery

http://dx.doi.org/10.1016/j.jtcvs.2015.12.011
}

Off-pump coronary artery bypass (OPCAB) is widely performed to reduce the risk due to cardiopulmonary bypass. Lifting and stabilizing the heart to expose the target coronary artery often increase pressure in the pulmonary artery or right atrium, which can cause right-to-left shunt in patients with a patent foramen ovale (PFO).

A-59-year-old man presented with effort angina and 2-vessel disease, but no major comorbidity. His ejection fraction was $65 \%$. OPCAB was scheduled. Transesophageal echocardiography (TEE) performed under anesthesia revealed a previously undetected PFO (Figure 1), but no shunt through it (Figure 2, A). As the heart was lifted for distal anastomosis of the right coronary artery, the blood oxygen saturation value $\left(\mathrm{Spo}_{2}\right)$ decreased from $99 \%$ to $86 \%$, and mixed venous oxygen saturation remained at approximately $58 \%$. There were no problems with the airway or ventilation. Right-to-left shunt through the PFO was revealed by TEE (Figures $2, B$, and 3 ). The diameter of the PFO was $4.3 \mathrm{~mm}$. The fraction of inspiratory oxygen $\left(\mathrm{FIO}_{2}\right)$ increased from 0.6 to 1.0 , and $\mathrm{SpO}_{2}$ increased to $92 \%$ in 5 minutes. No change in position was needed in completing anastomosis. The $\mathrm{SpO}_{2}$ value recovered immediately after the heart was returned to the normal position in a further 8 minutes. The patient was discharged without complications.

Reports of right-to-left shunt through a PFO during OPCAB are rare, ${ }^{1-4}$ and desaturation was reported in only 2 of these cases. ${ }^{1,2}$ Lifting of the heart to expose the diaphragmatic surface caused desaturation in both cases. When desaturation due to a $\mathrm{PFO}$ is detected, the $\mathrm{FIO}_{2}$ should be increased. With a pure intracardiac shunt, improvement in oxygenation may not be seen. Initiating cardiopulmonary bypass may be considered if desaturation remains severe even after increasing $\mathrm{FIO}_{2}$ to 1.0.
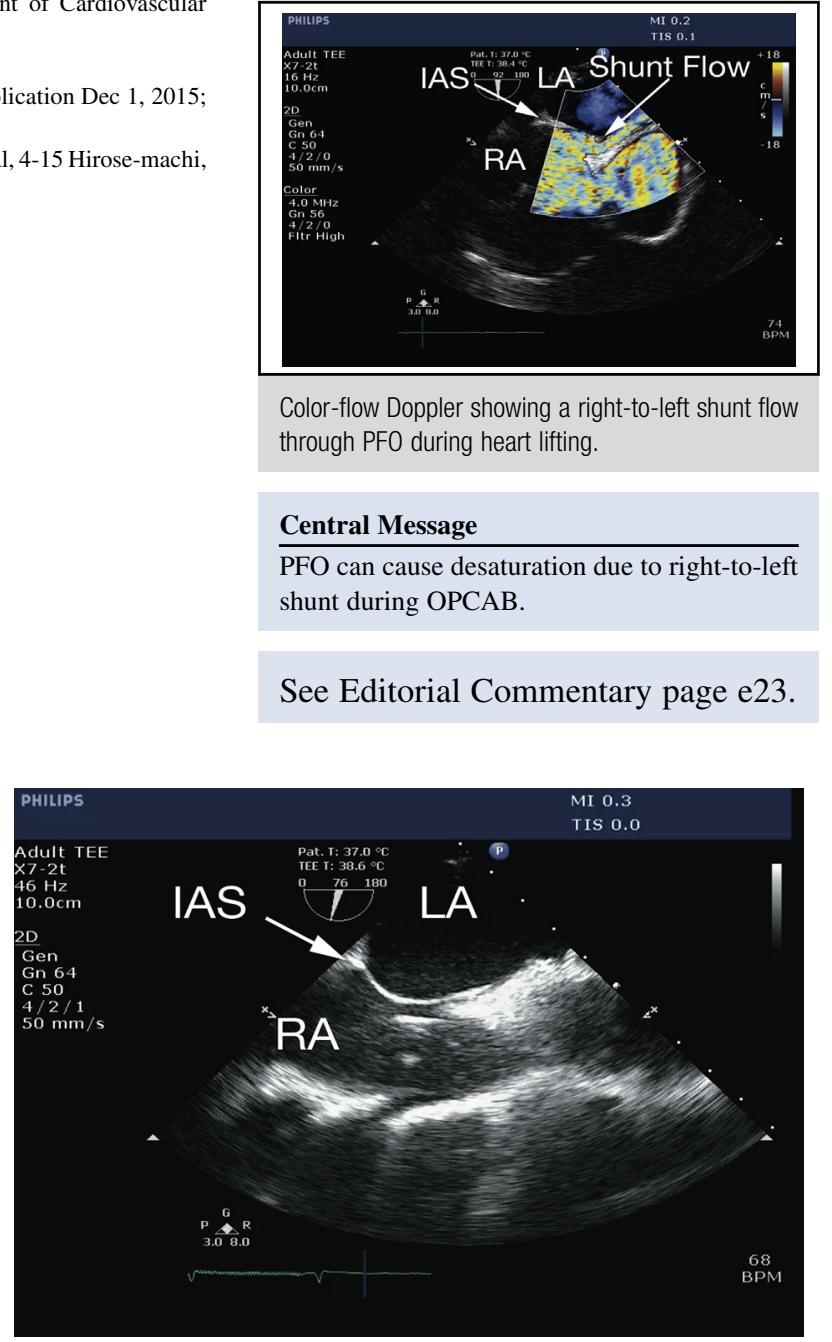

FIGURE 1. Mid-esophageal bicaval view shows previously undetected PFO with no shunt flow. TEE, Transesophageal echocardiography; $I A S$, Interatrial septum; $R A$, right atrium; $L A$, left atrium; $M I$, mechanical index; $T I S$, soft tissue thermal index.

OPCAB in patients with a PFO can cause desaturation. Intraoperative TEE may be useful in diagnosing the problem.

The authors thank Dr Kato Shigeaki at Sendai Kousei Hospital and Professor Jeremy Williams of the Department of International Medical Communications at Tokyo Medical University for assistance with the article. 


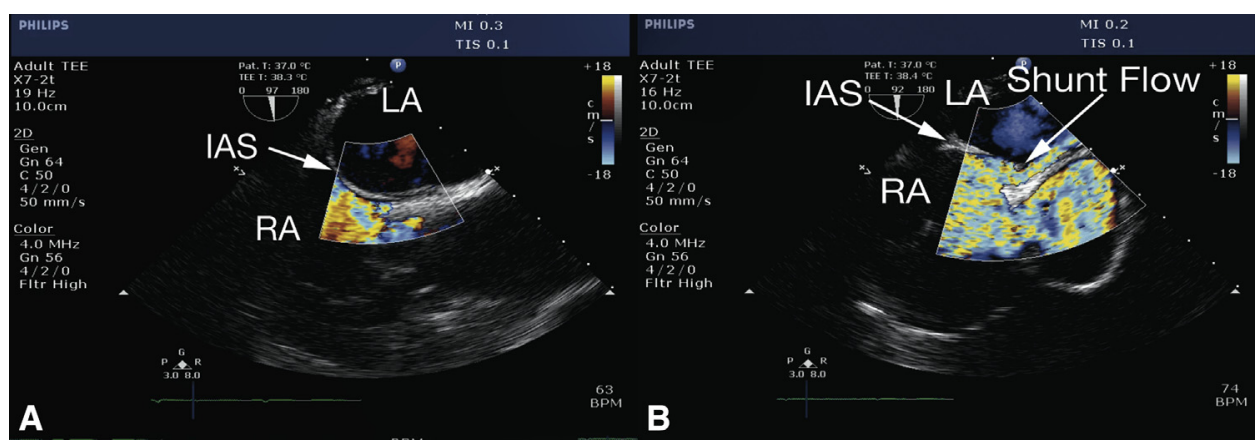

FIGURE 2. Mid-esophageal bicaval view with color-flow Doppler. A, PFO with no shunt flow while the heart was in normal position. B, PFO with right-toleft shunt flow during heart lifting. TEE, Transesophageal echocardiography; IAS, Interatrial septum; RA, right atrium; $L A$, left atrium; $M I$, mechanical index; TIS, soft tissue thermal index.

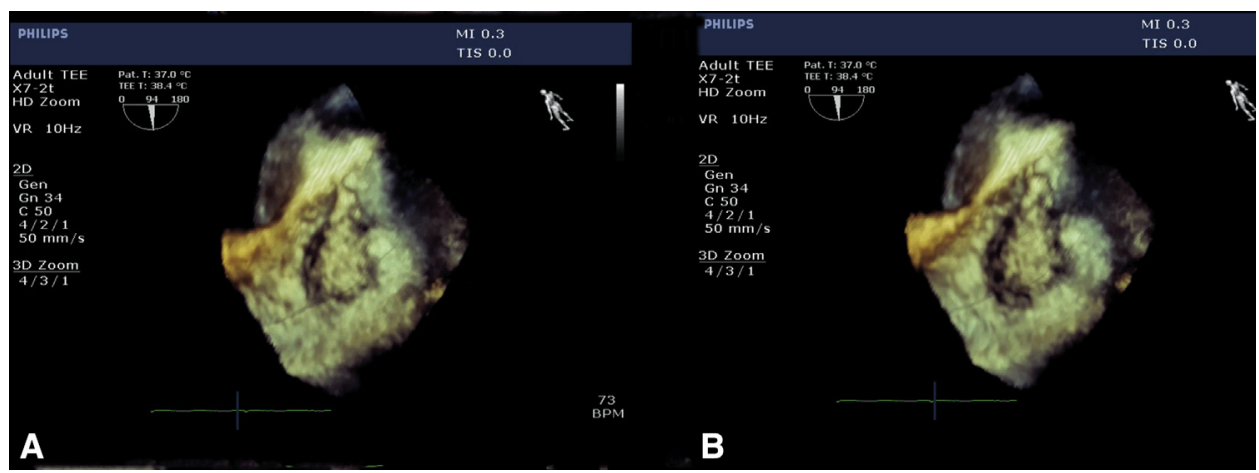

FIGURE 3. A 3-dimensional TEE image of PFO. A, Systolic phase. B, Diastolic phase. PFO was enlarged during diastolic phase. TEE, Transesophageal echocardiography; $M I$, mechanical index; TIS, soft tissue thermal index.

\section{References}

1. Akhter M, Lajos TZ. Pitfalls of undetected patent foramen ovale in off-pump cases. Ann Thorac Surg. 1999;67:546-8.

2. Periasamy S. Patent foramen ovale: a potential cause of refractory hypoxemia in off-pump coronary artery bypass surgery. J Cardiothorac Vasc Anesth. 2012;26: $38-9$

3. Sukernik MR, Mets B, Kachulis B, Oz MC, Bennett-Guerrero E. The impact of newly diagnosed patent foramen ovale in patients undergoing off-pump coronary artery bypass grafting: case series of eleven patients. Anesth Analg. 2002;95:1142-6.

4. Falcucci OA, Kasirajan V, Green JA. Transesophageal echocardiographic and oxymetric evidence of intraoperative reversal of flow through a patent foramen ovale during an off-pump coronary artery bypass grafting. J Clin Anesth. 2005;17:617-20. 